\title{
The role of information sharing-centered IT infrastructure factor by using advanced Metcalfe's law: Case study of Incheon International Airport
}

\author{
Hyodong Ha ${ }^{1}$, Hyunjong $\mathrm{Na}^{2}$, Ook $\mathrm{Lee}^{3}$ \\ ${ }^{1}$ Collaboration Professor (SW), Software Education Committee, Hanyang University, Seoul, Korea. \\ ${ }^{2}$ Ph.D. Student, Department of Computer Science and Engineering, Soongsil University, Seoul, Korea \\ ${ }^{3}$ Professor, Department of Information System, Hanyang University, Seoul, Korea. \\ ${ }^{1}$ ORCID: 0000-0001-9234-6380, ${ }^{2}$ ORCID: 0000-0003-3875-7896, ${ }^{3}$ ORCID: 0000-0003-4361-7927
}

\begin{abstract}
Many airports are continuously implementing Information Systems (IS) and Information Technology (IT) services in order to achieve their organizational objectives. Such IS, known as nodes in distributional environment, are systematically interconnected to share information and thereby increase task performance efficiency. As importance of information sharing arise, strategic management of nodes that surround Information Integration System (IIS) has become essential. This paper suggests application plan of Enterprise Application Integration (EAI) installed IIS based on case study of which previously has been implemented in Incheon International Airport, and further estimates effects on the organizational output. We have calculated and analyzed advanced Metcalfe's law applied EAI network power of interconnected nodes of IIS between year 2014 and 2018. Moreover, we performed multiple regression analysis in order to derive statistical impact of EAI network power on the organizational output as an IT infrastructure. The result indicates exponential increase in EAI network power for increased number of nodes. And the number of flights, which is organizational output of the airport, is affected by 3 factors in decreasing order - firm strategy, IT infrastructure, and firm culture. Therefore, we conclude that quantification of internal system via managing number of nodes can be used as evidence for Key Performance Indicator (KPI) to aid organizational decision making.
\end{abstract}

Keywords: Information Sharing, Information Integration System, EAI, Metcalfe's Law, IT Interaction Model

\section{INTRODUCTION}

An organization can create business values via information analysis in this big data era [1]. However, value of information may change as time passes, therefore strategic management of the information is required [2]. Based on such needs, various organizations are currently devoted to information sharing, and are implementing and operating the Information Integration System (IIS). IIS is an integrated form of Information Systems (IS) which supports information sharing and system connections based upon interoperability [3]. For example, Sejong city supports various u-services to citizens through a newly implemented system called ubiquitous city (also known as smart city) which mutually shares information between integrated land information system and administration information system [4]. Ministry of Interior and Safety (MOIS) implemented administration information sharing center in order for various organizations to share and process their tasks, and such effort for information sharing has been chosen as outcome indicator for prompt information sharing [5]. Moreover, many airports are implementing and operating information sharing-centered systems such as context aware platform of Melbourne airport and flight information sharing system of Beijing Daxing airport which connects 70 other systems [6][7].

In terms of airports' information sharing service, there are vertically and horizontally integrated stakeholders, and all individuals may have to contribute in the organization's resource and knowledge in order to create new values [8]. Number of IS (known as node in distributed environment) which shares information of the airport is increasing, but the measurement and quantification of performance increased by information sharing is still difficult. Benefits of IS can be classified into tangible benefits - decrease in process errors and increase in throughput - and intangible benefits - increase in service quality and improved decision making. Such benefits, however, should be quantified in order to carry out proper cost-effectiveness analysis [9]. Korean National Information Society Agency suggests applying number of nodes as basis for cost, if the system is implemented for internal use or specific processes [10].

Previous researches on number of nodes connected to IIS, however, is insufficient. Therefore, this paper suggests application plan of Enterprise Application Integration (EAI) installed IIS based on case study of which previously has been implemented in Incheon International Airport. We have calculated and analyzed advanced Metcalfe's law applied EAI 
network power of all nodes connected to airports' IIS from year 2014 to 2018, and the EAI network power is used as a factor of IT infrastructure. Based on framework provided by IT interaction model of Silver, Markus, \& Beath (1995), we have performed multiple regression analysis on number of flights against input variables - Incheon Airport's firm strategy and culture, and IT infrastructure. By analyzing IIS and nodes surrounding through a case study, we suggest an application plan for quantitative measuring of IIS performance. Moreover, empirical study is carried out for internal factors which have effect in airport's output in order to statistically verify EAI network power's effectiveness.

This study aims to offer help in decision making for airport operators and stakeholders by means of data-oriented strategic management of nodes.

\section{LITERATURE REVIEW}

\subsection{Information Integration System of Incheon International Airport}

Incheon International Airport is a Korean international airport which started its operation in 2001. The airport is continuously extending its facility scale, aiming for 790 thousand flights, 100 million passengers, and 6.3 million tons of cargo carriage yearly. Concourse was opened in June 2008 and Passenger terminal 2 in January 2018. Along with the facility extension, IIS has been implemented as shown in table 1 below.

Table 1. Flight information IIS levels for extended levels of operation

\begin{tabular}{|l|c|c|c|}
\hline & Level 1 & Level 2 & Level 3 \\
\hline Operation & $\begin{array}{c}2001.3 \\
\sim 2008.5\end{array}$ & $\begin{array}{c}2008.6 \\
2017.8\end{array}$ & $\begin{array}{c}2017.09 \\
\sim \text { present }\end{array}$ \\
\hline Software & IH & EAI v2.4 & EAI v3.5 \\
\hline $\begin{array}{l}\text { Number } \\
\text { of Nodes }\end{array}$ & 39 & $\begin{array}{c}43 \text { (start of level 2) } \\
49 \text { (end of level 2) }\end{array}$ & $\begin{array}{c}77 \text { (start of } \\
\text { level 3) }\end{array}$ \\
\hline $\begin{array}{l}\text { Notes: Incheon International Airport's official materials, } \\
\text { newspaper, public enterprises' business result reports, } \\
\text { request for proposals of system implementation, etc. used as } \\
\text { reference }\end{array}$ \\
\hline
\end{tabular}

Socket based middleware, information hub (IH), was installed in 2001 for information sharing of the airport. More than 80 operating systems were integrated into 39 [11]. The systems were integrated into EAI during operation phase 2. In 2011, the EAI has been divided into Operation EAI responsible for flight operation, and Management EAI responsible for enterprise resource planning (ERP) integration [12]. Number of nodes for information sharing has increased from 43 to 49 throughout operation phase 2. The upgraded EAI has been implemented during operation phase 3 as terminal 2 was opened. Previous system processed approximately 3 million transactions, where the new integrated system processed more than twice (6 million) using 77 nodes [13].
Key point in airport management is to provide the most recent information of interest to various stakeholders [14]. Making use of information obtained from IIS will reduce personnel's turn-around time, and diverse resource will enhance task performance efficiency [15]. Moreover, such obtained information directly affects the passengers' service satisfaction. Rhoades, Waguespack, \& Young have statistically proven that visual display of airport's information has significant impact on the passengers' service quality recognition [16]. On the other hand, IT troubles leading to failure of information provision, including Bristol airport incident where flight information display has gone blackout, will cause not only dissatisfaction of passengers but also airport management risks [17]. Figure 1 describes Incheon International Airport's schedule sharing, where the processes are grouped according to information provider, IIS, and information consumer.

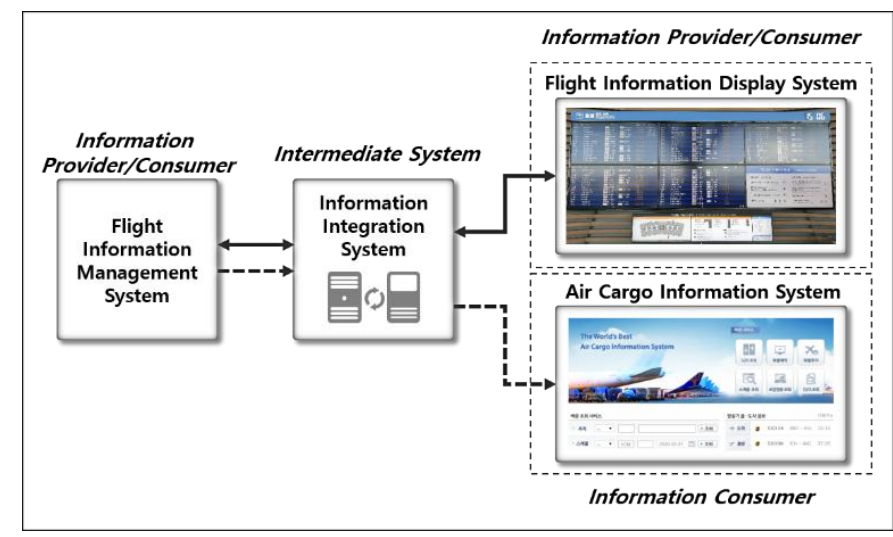

Fig. 1. Example of airport schedule sharing

Flight information management system (FIMS) analyzes and manages airport's flight information including plane departure/arrival and flight scheduling [18]. Flight information display system (FIDS) offers visual guide on flight information within the airport. Air cargo information system (AIRCIS) supports task processing among the cargo subjects and provides flight cargo information. IIS distributes flight information retrieved from FIMS to FIDS and AIRCIS officers.

\subsection{Metcalfe's Law}

Advancement in computer and digital communication technologies led to high diffusion of internet, which eventually facilitated studies that have tried to quantitatively measure the value of network. Metcalfe, applying Moore's law which states that performance of semiconductor integrated circuit doubles every 24 months, suggested that value of network is proportional to square of number of digital communication devices [19]. Moreover, this rule-of-thumb number of devices - has been replaced with number of users and widely represented the concept of network effects. As the number rapidly increases, Read suggested $2^{n}$, and Odlyzko and Tilly suggested $n * \log (n)$ for the value measurement of 
network [20][21]. On the other hand, Metcalfe used Facebook data, and Zhang, Liu, \& Xu used Tencent data to verify their concept [19][22]. Nickerson and Olariu suggested Metcalfe's law applied model which took latency time among the systems into consideration [23]. Jung, Lee, \& Kim suggested network power using advanced Metcalfe' law in order to measure command, control, communication, computer, and intelligence (C4I) of military tactical system [24]. While Metcalfe' law assumes that all nodes have the same value and share the same amount of information, advanced models apply different weight for different nodes, and apply weight of node link for each node. The expression is as below.

\section{Network Power $=$}

$$
\sum_{i=1}^{n} \operatorname{Node}_{i}+\sum_{i=1}^{n} \sum_{j=1}^{n} \operatorname{Node}_{i} \operatorname{Link}_{i j}(i \neq j)
$$

Unlike Facebook and Tencent where the system is used by various and multiple users, system for internal use has limits in applying Metcalfe's law. This study applies formula 1 in order to measure network power for IIS and nodes of Incheon International Airport. Physical distance of nodes from the IIS varies one another, but thanks to computing and network technologies, the transaction times of adaptors installed in node interfaces have shown no significant difference. Therefore, we assume there is no latency time which Nickerson and Olariu suggested.

\subsection{Classification according to organization context}

Silver, Markus, \& Beath suggested IT interaction model for teaching method of students of Master of Business Administration Course [25]. Organizational context determines the feature of IS and interacts with. Consequently, the background determines the actual usage of IS, and the result will be output intended or not intended. For example, according to Lee and Gong, despite prevalent Confucianism in Korea, vocabularies showing respect have not been detected in government website boards, unlike those email communications [26]. It is suggested that usage of such portal systems may relieve Confucian psychology issues and aid more direct communications. Based on the previous study, Piccoli assigned firm strategy, firm culture, and IT infrastructure as internal factors of organization context [27]. Definitions of each are as below.

- Firm strategy: method for accomplishing organization objectives

- Firm culture: assembly of trust, expectation and values shared by organization members

- IT infrastructure: set of IT resources and services shared within organization

In this paper, the background survey for the factors above is conducted for Incheon International Airport.
First is firm strategy. As demand for airports of northeast Asia increases, all countries are competing to build their airport as a hub in the region. As a consequence, various studies have been conducted focusing on competency of airport. According to Chae and Kim, Asian Pacific airports are actively attracting low cost carrier (LCC) to become a hub, and such increase in LCC is verified to affect airport management efficiency [28]. Park measured competency of main airports in East Asia. Park suggested among the core factors, demand, which represents origin-destination level, is the most important factor [29]. Park also suggested that the number of airlines, which is a sub factor, may represent an airport's grade level [29]. Loo has verified that the number of airlines in airport have effect on passengers' choosing of the airport [30]. Eie, Hong, \& Park used number of airlines to study competency of Korean and Japanese airports [31]. Table 2 describes number of airlines in Incheon International Airport from year 2014 to 2018.

Table 2. Number of airlines for year 2014 to 2018

\begin{tabular}{|l|c|c|c|c|c|}
\hline & $\mathbf{2 0 1 4}$ & $\mathbf{2 0 1 5}$ & $\mathbf{2 0 1 6}$ & $\mathbf{2 0 1 7}$ & $\mathbf{2 0 1 8}$ \\
\hline Number & Min: & Min: & Min: & Min: & Min: \\
of & 77 & 77 & 79 & 84 & 86 \\
airlines & Max: & Max: & Max: & Max: & Max: \\
& 85 & 85 & 85 & 92 & 93 \\
\hline Notes: Statistics from Incheon International Airport's \\
official website has been recomposed. Search options \\
include number of monthly passenger and cargo planes of \\
all airlines.
\end{tabular}

Based on the studies mentioned above, number of airlines is used as base data for firm strategy in this paper.

Second is firm culture. Even though possibility of airline traffic accident is very low, minor mistake or technical error is likely to cause fatal consequence. Preventive measure for such, therefore, is required [32]. There was a plane crash incident of Continental Express in 1991, and the safety culture has been noted as a reason for accident [33]. Many airports' safety management standards have been established from then, and foundation of safety culture has been recommended. EUROCONTROL developed ATM safety framework maturity survey after plane crash accident in Linate, 2001, and in Überlingen, in 2002 [34]. Moreover, the survey and measurement are annually conducted for European regulatory institutions and navigation service providers, and the organization members are internalizing the safety management system requirements in order to satisfy the safety objectives. Ministry of Economy and Finance in Korea annually inspects and evaluates airport safety managements measured for Incheon International Airport. Airport safety management measures include accident count (plane accident, semi-accident, accident on land), landing field breakdown count, external inspection, and comment count (airport safety operation system periodic inspection and seasonal flight traffic safety inspection) in order to evaluate effort for safe flight [35]. Table 3 below describes number of accidents, breakdowns and comments counts of Incheon International Airport, and its average per month. 
Table 3. Airport safety management counts per year

\begin{tabular}{|c|c|c|c|c|c|}
\hline $\begin{array}{c}\text { Accidents, } \\
\text { breakdowns, } \\
\text { and } \\
\text { comments } \\
\text { count (total) }\end{array}$ & $\mathbf{2 0 1 4}$ & $\mathbf{2 0 1 5}$ & $\mathbf{2 0 1 6}$ & $\mathbf{2 0 1 7}$ & $\mathbf{2 0 1 8}$ \\
\hline $\begin{array}{c}\text { Accidents, } \\
\text { breakdowns, } \\
\text { and } \\
\text { comments } \\
\text { count } \\
\text { (total/12) }\end{array}$ & 0.583 & 0.167 & 0.167 & 0.25 & 0.083 \\
\hline $\begin{array}{c}\text { Notes: Public enterprise } 2018 \text { annual business result report } \\
\text { has been recomposed. }\end{array}$ & 2 & 2 & 3 & 1 \\
\hline
\end{tabular}

In this paper, accident, breakdown and comment counts are used as base data for firm culture. However, there is no way to directly know on which month the incident happened. Therefore, we used the counts divided by 12 .

Third is IT infrastructure, and we refer to flight centered Operation EAI in this paper. Number of nodes from year 2014 to 2018, of operation phase 2 and 3 from 2.1, are calculated using formula 1 from 2.2, and is used as base data for IT infrastructure. Information on nodes are acquired from Incheon International Airport's official materials, newspaper, public enterprises' annual business result reports, request for proposals of system implementation, etc., and validity of the information has been confirmed through interview with system engineers and operators.

\section{MODEL DEVELOPMENT}

\subsection{EAI network power model development}

Figure 2 describes development procedure of EAI network power for flight centered Operation EAI of Incheon International Airport.

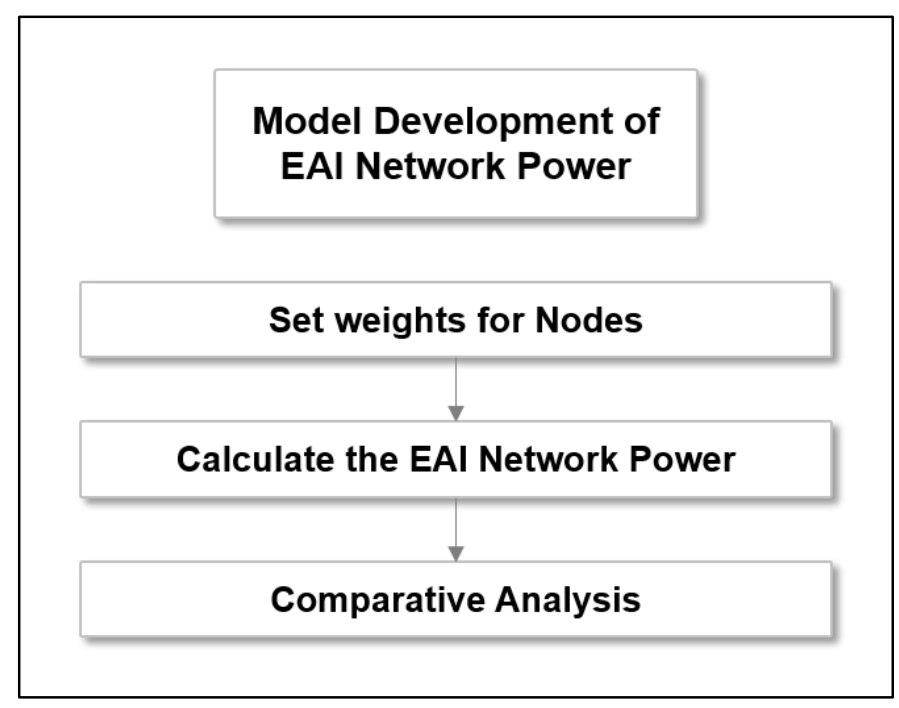

Fig. 2. EAI network power calculation procedure
First, we set weight of nodes from IIS perspective. In this paper, weight is determined by reviewing system transition group list written during the stage between operation phase 2 and 3 [36]. If the system test is successful during IS implementation stage, the transition is finally confirmed. The existing level 2 system of the airport is then transited through 4 sub steps. Weightage decision for nodes of operation phase 3 is determined through evaluation on three factors; impact of airport management, extent of need for real time information sharing, and public service from airport's perspective in case of information sharing being disabled. The weights are classified into 4 (very high, high, average, low) according to its importance.

Second, EAI network power from January 2014 to December 2018 is calculated. Formula 1 is applied, and node creation, removal, and integration per month are reflected.

Third, comparison analysis on EAI network power is conducted. Comparison distinguished by whether the weight is applied to nodes of operation phase 2 and 3 , and comparison with Metcalfe' law, Odlyzko and Tilly's law is conducted.

\subsection{Organizational context and output}

From previous literature review in 2.3 , we have noticed that 3 internal factors of organization context, firm strategy, firm culture, IT infrastructure, are organizational resource and capability. In this paper, we verify the effect of the internal factors on airport's output. Figure 3 is a research model on the internal factors and airport output.

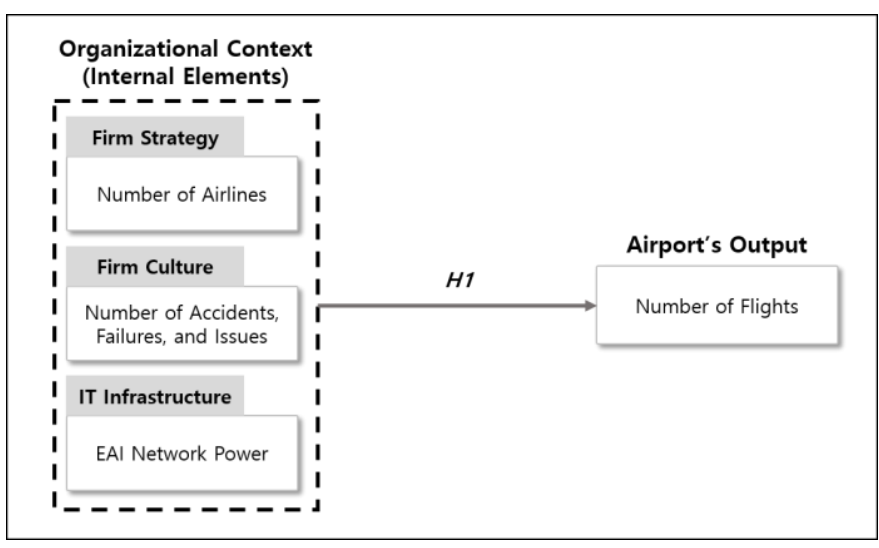

Fig. 3. Research model on the internal factors of organization context and airport output

An airport is designed from perspective view of passenger and cargo, connects numerous organizations, and is organically operated [37]. Operation EAI supports the workflow via information sharing. Each node accomplishes its objective, and all activities come into a conclusion, a proper flight. Therefore, we consider total monthly flights as output of the airport. In this paper, instead of predicting through regression 
International Journal of Engineering Research and Technology. ISSN 0974-3154, Volume 13, Number 10 (2020), pp. 2752-2760

(C) International Research Publication House. https://dx.doi.org/10.37624/IJERT/13.10.2020.2752-2760

analysis, we verify the effect of each factors on airport's output.

Hypothesis 1: Organizational context (firm strategy, firm culture, and IT infrastructure) influences airport's output

\section{MODEL VERIFICATION}

\subsection{Analysis of EAI network power}

We calculated and reviewed weights of nodes for EAI network power from IIS perspective, and final weightage is determined through interview with operators. For example in Figure 1, FIMS was weighted very high, FIDS was weighted very high, and AIRCIS was weighted low. Figure 4 describes node's weightage in September 2017.

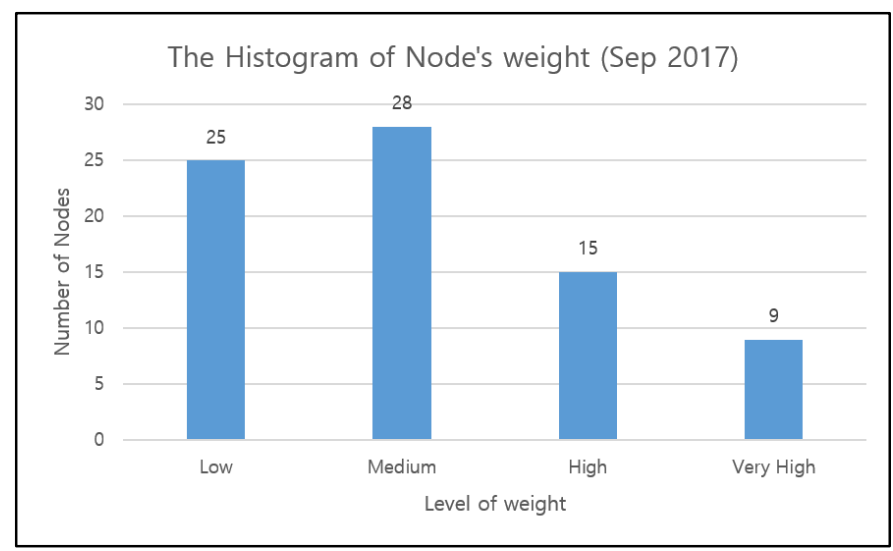

Fig. 4. Histogram of node's weight

EAI network power is then calculated based on the assigned weights. For example, EAI network power in Figure 1 is 21. FIMS and FIDS perform transmission back and forth, while AIRCIS only receives message from FIMS. Depending on the weight and direction of information sharing, the calculation appears as below.

$$
\begin{array}{ll}
- & \text { FIMS = 12(4+(4*2)) } \\
- & \text { FIDS = 8 (4+(4*1)) } \\
- & \text { AIRCIS = 1 }(1+(1 * 0))
\end{array}
$$

* Weight level (Very high: 4, High: 3, Medium: 2, Low: 1)

As calculation results shown in Figure 5, EAI network power slowly increased over time, and extensively increased at certain point of time, showing typical S curve graph.

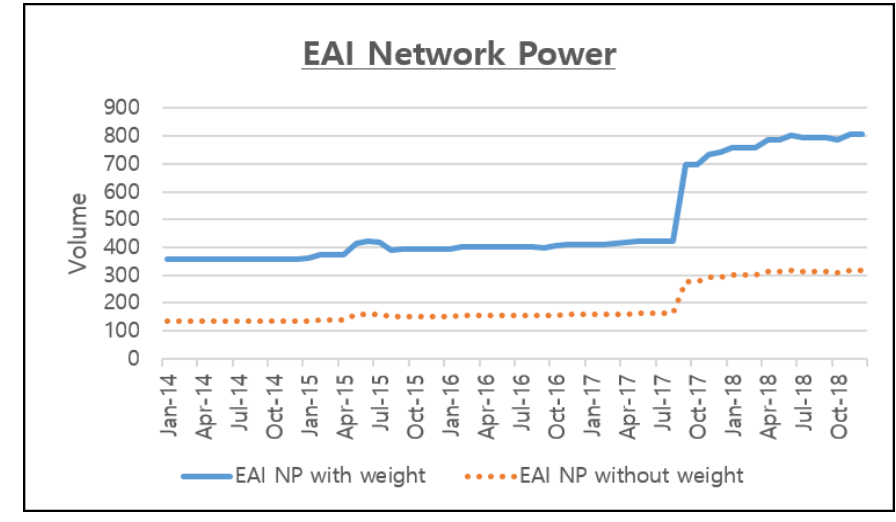

Fig. 5. EAI network power

Figure 6 describes EAI network power per operation phase 2 and 3. From January 2014 to August 2017, number of nodes of level 2 increased from 45 to 49 . Having weights into consideration, EAI network power calculated within period of time has shown to increase from 358 to 421 . From September 2017, where operation phase 3 has started, to December 2018, number of nodes increased from 77 to 85 and EAI network power increased from 697 to 807. Gradient for operation phase 2 and 3 is calculated to be 12.467 and 13.537 respectively. EAI network power in operation phase 2 without having weights into consideration, however, is calculated to increase from 134 to 162 , and for operation phase 3, 275 to 315; gradient for the two levels were calculated to be 5.4482 and 4.8774. Gradient may differ upon fine tuning of node weightage, and such fact can be put into consideration depending to the organization's situation.

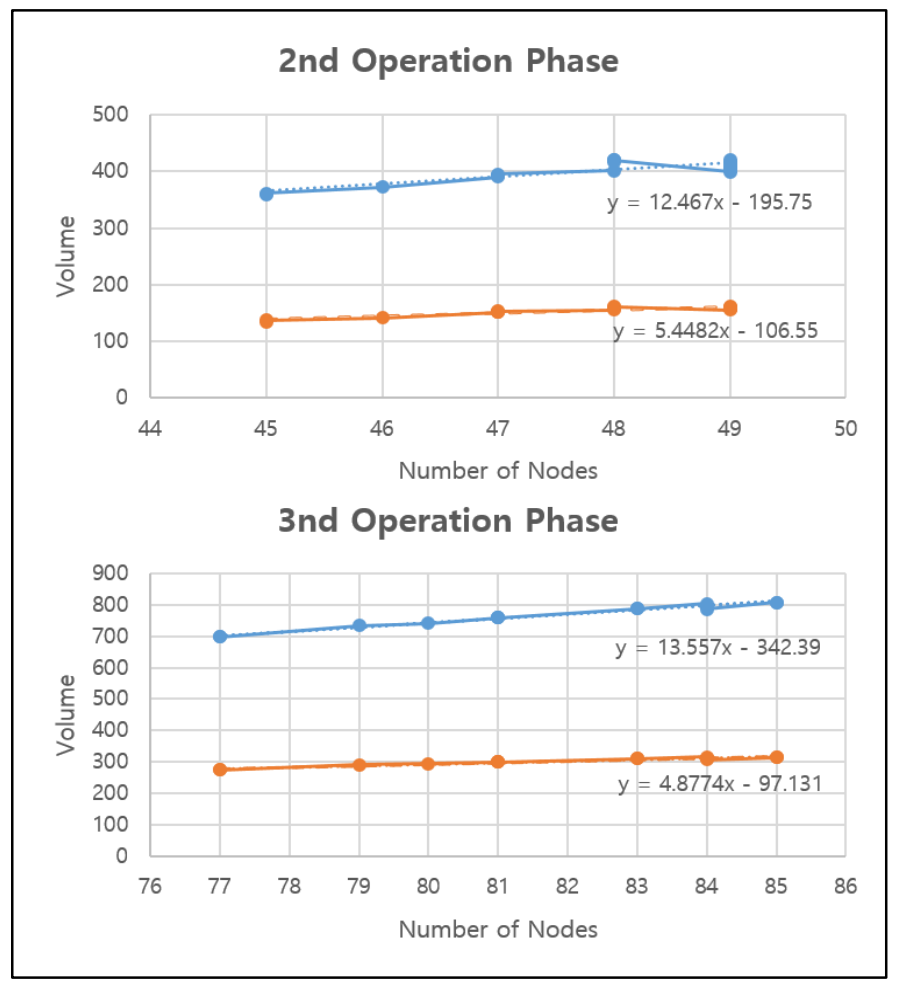

Fig. 6. EAI network power per operation phase 
Figure 7 is a comparison graph of Metcalfe's law, Odlyzko and Tilly' law. EAI network power has shown approximately 1.5 times higher volume as compared to $n * \log (\mathrm{n})$ of Odlyzko and Tilly's law. As compared to $n^{2}$ of Metcalfe's law, 5 8 times difference has been shown. Despite EAI network power having node weightage into consideration and having basis of Metcalfe's law, significant difference can be noticed. Such finding can be interpreted in terms of graph area. Section below EAI network power is an area where actual information sharing is taking place, and section between $n^{2}$ and EAI network power is an area of opportunity for new service implementation. Company-wide improvement of IS and expansion of information sharing may trigger process innovations, leading to improvement in capability and task processing improvement. From this point of view, an organization has to increase the area size of $\frac{\text { EAI network power }}{n^{2}}$ by identifying unrecognized information sharing services.

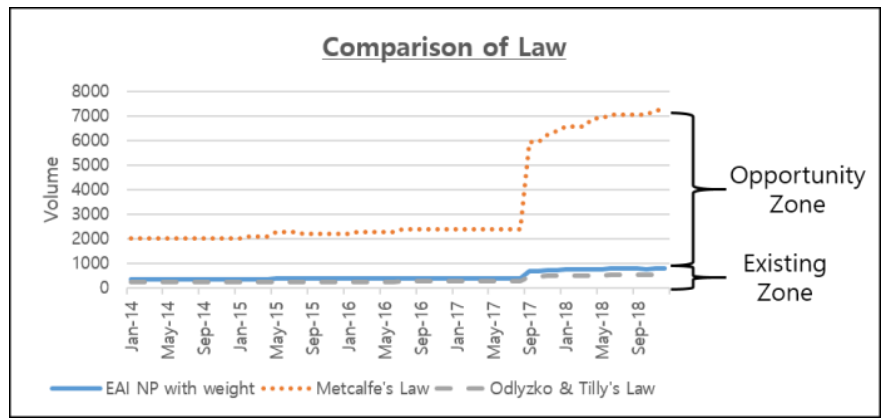

Fig. 7. Comparison of law

We have estimated for the exponent using deduced EAI network power, and the value is shown to be in between 1.5 and 1.6 as shown in Figure 8. Estimation without having weightage into consideration has shown exponent value between 1.2 and 1.4. According to interview conducted by Park, Kim, \& Sim against airport officers, the most limitation in Big data analysis lies within absence of data management, thereby insists integrated airport data management center has to be implemented for Big data analysis [38]. Shin, Kim, \& Lee identified Internet of things (IoT) and Big data as technical factors that will affect long term strategy direction of Incheon International Airport [39]. Furthermore, they suggest implementation of integrated system and application of IoT and Big data to the airport in order to enhance operation efficiency, timeliness, and customized services. Increase in exponent value of EAI network power is expected through active information sharing via future implementation of IoT based IS (e.g. drone system) and stabilization of Big data analysis environment.

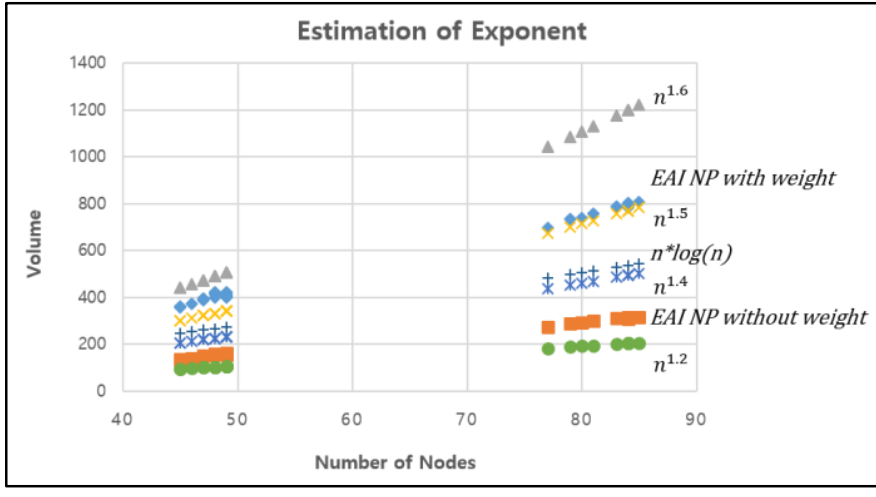

Fig. 8. Estimation of exponent

Based on the analysis above, we can classify growth of EAI network power into qualitative and quantitative growth as shown in Figure 9. Qualitative growth indicates discovery of new information sharing service without increase in number of nodes, while quantitative growth indicates addition of new nodes. As an organization distinguishes and identifies current status of both growths, quantitatively manages internal systems that are difficult to measure the output, and measures efforts for information sharing, the acquired results can be used as base data of key performance indicator (KPI) for decision making.

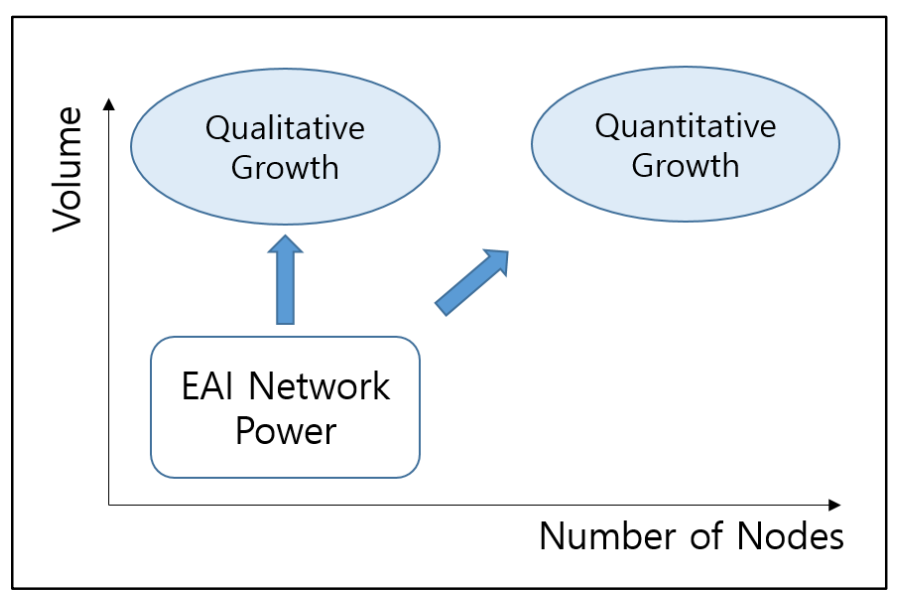

Fig. 9. Growths of EAI network power 
Table 4. Model summary and ANOVA

\begin{tabular}{|c|c|c|c|c|c|c|}
\hline \multirow{2}{*}{$\begin{array}{c}\text { Model } \\
\text { Summary }\end{array}$} & Model & $\mathbf{R}$ & R Square & $\begin{array}{c}\text { Adjusted R } \\
\text { Square }\end{array}$ & $\begin{array}{c}\text { Std. Error of } \\
\text { the Estimate }\end{array}$ & Durbin-Watson \\
\cline { 2 - 7 } & 1 & .896 & .803 & .792 & 1468.96893 & 1.394 \\
\hline \multirow{4}{*}{ ANOVA } & Model & $\begin{array}{c}\text { Sum of } \\
\text { Squares }\end{array}$ & df & Mean Square & F & Sig. \\
\cline { 2 - 7 } & Regression & 491979284.143 & 3 & 163993094.714 & 75.998 & .000 \\
\cline { 2 - 7 } & Residual & 120840704.591 & 56 & 2157869.725 & & \\
\cline { 2 - 7 } & Total & 612819988.733 & 59 & & & \\
\hline
\end{tabular}

Table 5. Coefficients

\begin{tabular}{|c|c|c|c|c|c|c|c|}
\hline \multirow{2}{*}{ Model } & \multicolumn{2}{c|}{$\begin{array}{c}\text { Unstandardized } \\
\text { Coefficients }\end{array}$} & $\begin{array}{c}\text { Standardized } \\
\text { Coefficients }\end{array}$ & \multirow{2}{*}{ t } & \multirow{2}{*}{ Sig. } & $\begin{array}{c}\text { Collinearity } \\
\text { Statistics }\end{array}$ \\
\cline { 3 - 5 } \cline { 3 - 7 } & B & Std. Error & Beta & & VIF \\
\hline \multirow{2}{*}{$\mathbf{1}$} & (Constant) & -4557.108 & 5282.867 & & -.863 & .392 & \\
\cline { 2 - 8 } & Firm strategy & 371.326 & 68.322 & .461 & 5.435 & .000 & 2.044 \\
\cline { 2 - 8 } & Firm culture & -5396.365 & 1277.045 & -.295 & -4.226 & .000 & 1.386 \\
\cline { 2 - 8 } & IT infrastructure & 5.767 & 1.707 & .307 & 3.378 & .001 & 2.341 \\
\hline
\end{tabular}

\subsection{Verification of internal factors of organization context}

We performed multiple regression analysis for internal factors and airport's output from January 2014 to December 2018, using SPSS Statistics v24. As correlation analysis results shown is Figure 10, all factors are significant in 0.05 level, correlation coefficient between output and firm strategy shows 0.802 indicating very high correlation. Output versus firm culture and IT infrastructure has shown -0.646 and 0.790 , indicating high correlation.

\begin{tabular}{|ll|r|r|r|r|}
\hline & \multicolumn{5}{c|}{ Correlations } \\
& & Flights & Firm_Strategy & Firm_Culture & IT_Infra \\
\hline Pearson Correlation & Flights & 1.000 & .802 & -.646 & .790 \\
\cline { 2 - 7 } & Firm_Strategy & .802 & 1.000 & -.412 & .713 \\
\cline { 2 - 7 } & Firm_Culture & -.646 & -.412 & 1.000 & -.525 \\
\cline { 2 - 7 } & IT_Infra & .790 & .713 & -.525 & 1.000 \\
\hline \multirow{3}{*}{ Sig. (1-tailed) } & Flights & .000 & .000 & .000 \\
\cline { 2 - 7 } & Firm_Strategy & .000 & .000 & .001 & .000 \\
\cline { 2 - 7 } & Firm_Culture & .000 & .001 &. & .000 \\
\cline { 2 - 7 } & IT_Infra & .000 & .000 & .000 & \\
\hline N & Flights & 60 & 60 & 60 & 60 \\
\cline { 2 - 7 } & Firm_Strategy & 60 & 60 & 60 & 60 \\
\cline { 2 - 7 } & Firm_Culture & 60 & 60 & 60 & 60 \\
\cline { 2 - 7 } & IT_Infra & 60 & 60 & 60 & 60 \\
\hline
\end{tabular}

Fig. 10. Correlation analysis

Model summary of Table 4 describes $R^{2}$, which is the percentage of the variance in the dependent variable that the independent variables explain collectively, is 0.803. DurbinWatson is 1.394 and is shown to lie under the uncertainty zone in between $d_{L}$ and $d_{U}(1.317 \sim 1.520)$ of 0.01 standard depending on the sample size. Analysis performance, therefore, is continued considering Durbin-Watson having no autocorrelation. A p-value in ANOVA is indicated to be significant in 0.05 level.

In Table 5, internal factors of organization context are shown to be statistically significant in 0.05 level, and we can assume there is no multicollinearity problem as all VIF are shown to be less than 10. The standardized coefficient of EAI network power is 0.307. Standardized coefficient comparison could determine which independent variables have greater influence on the dependent variable. As shown in table 5, firm strategy, IT infrastructure, and firm culture have effect on flight in decreasing order.

\begin{tabular}{|c|c|c|c|c|c|}
\hline \multicolumn{6}{|c|}{ Residuals Statistics ${ }^{a}$} \\
\hline & Minimum & Maximum & Mean & Std. Deviation & $\mathrm{N}$ \\
\hline Predicted Value & 22951.8809 & 33904.0195 & 28049.2333 & 2887.66895 & 60 \\
\hline Std. Predicted Value & -1.765 & 2.028 & .000 & 1.000 & 60 \\
\hline $\begin{array}{l}\text { Standard Error of } \\
\text { Predicted Value }\end{array}$ & 240.819 & 669.740 & 371.503 & 77.086 & 60 \\
\hline Adjusted Predicted Value & 22821.3906 & 34379.1445 & 28052.9068 & 2892.43454 & 60 \\
\hline Residual & -4002.02148 & 3246.14404 & .00000 & 1431.13505 & 60 \\
\hline Std. Residual & -2.724 & 2.210 & .000 & .974 & 60 \\
\hline Stud. Residual & -2.882 & 2.280 & -.001 & 1.008 & 60 \\
\hline Deleted Residual & -4477.14502 & 3456.07471 & -3.67343 & 1533.76604 & 60 \\
\hline Stud. Deleted Residual & -3.094 & 2.373 & -.004 & 1.034 & 60 \\
\hline Mahal. Distance & .602 & 11.281 & 2.950 & 1.720 & 60 \\
\hline Cook's Distance & .000 & .246 & .018 & .037 & 60 \\
\hline Centered Leverage Value & .010 & .191 & .050 & .029 & 60 \\
\hline
\end{tabular}

Fig. 11. Residuals statistic

Lastly for verification of anomaly, we reviewed standardized residual (ZRE) and Cook distance. As shown in Figure 11, highest residual from the absolute value is -2.72437 , and Cook distance is 0.24645 . As both values are less than reference 
values 3.0 and 1.0 respectively, we consider there is no anomaly.

For verification of the regression model, we reviewed homoscedasticity and normality of residuals. As shown in Figure 12, no particular anomaly can be seen among predicted values and residuals from 0 , thus, satisfying homoscedasticity. Significance probabilities of Kolmogorov-Smirnov and Shapiro-Wilk are 0.2 and 0.344 respectively, which satisfy normality of standardized residual, as the value is greater than 0.05. We can consider Hypothesis 1, therefore, is valid.

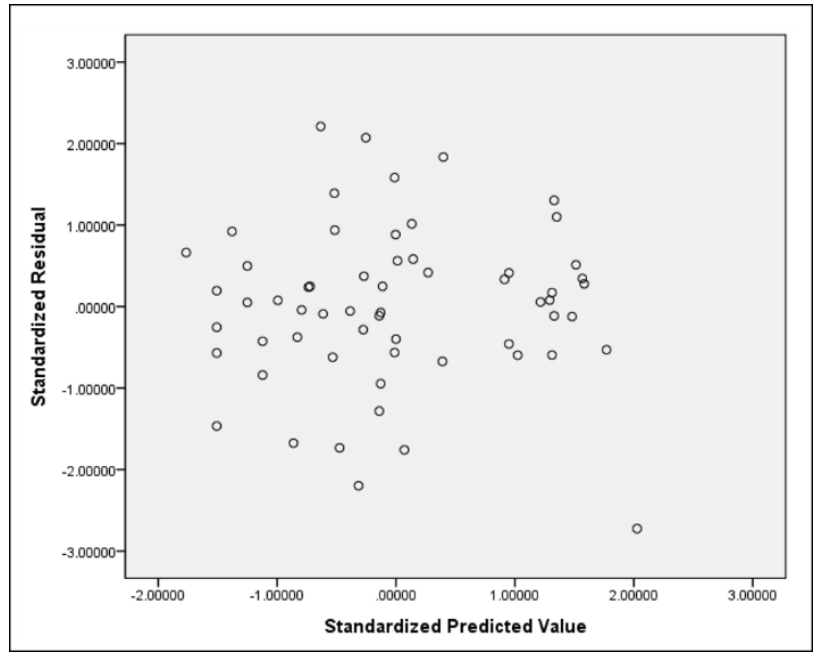

Fig. 12. homoscedasticity of residuals

\section{CONCLUSION}

Incheon International Airport is currently facing requirements for creation of new business values and adoption to rapidly changing environments, just as all other airports in East Asia region. The organization is constantly implementing new IT services through implementation - activation - discard life cycle. Within the context, number of nodes surrounding IIS is changing in real time along with increase in throughput of shared information.

Subsequently, this paper proposes application plan of IIS in accordance with change in number of nodes. Empirical study on case of Incheon International Airport which implemented hub \& spoke type EAI is conducted. We developed EAI network power with nodes weighted from year 2014 to 2018 . Analysis result shows s-curve throughout the operation phases, and application of node weights has shown difference of approximately 2.6 times. Gradient of the graph, however, has shown no significant difference regardless the application of node weights. As number of nodes increase, EAI network power was measured slightly greater than $n * \log (n)$, while significant difference was shown against $n^{2}$. Such difference implies that it is a field to be pioneered with new information sharing services. The developed EAI network power is used as IT infrastructure, one of the 3 internal factors of organization context, and is used along with other 2 factors - firm strategy and firm culture - for multiple regression analysis against airport's output. All factors have shown to be statistically significant. Moreover, we verified that number of airlines, EAI network power, and accident, breakdown, comment counts have effect on number of flights in decreasing order.

Based on the study results, we expect that measurement of information sharing effort and quantitative management of nodes sharing information can be used as base data for KPI. As mentioned earlier, the limitation of this study is that it does not represent the whole Incheon International Airport's information sharing - only flight information centered system is put into consideration, and system such as AIRCIS, responsible for cargo information, is not covered in this paper. Another limitation may be absence of analysis on creation and consumption process of information within nodes. Future studies should be conducted having analysis on whole airport's IIS into consideration, in order to certainly improve the airport's output and performance.

\section{REFERENCES}

[1] Watson, H. J. (2014). Tutorial: Big data analytics: Concepts, technologies, and applications. Communications of the Association for Information Systems, 34(1), 65.

[2] Tallon, P. P. (2013). Corporate governance of big data: Perspectives on value, risk, and cost. Computer, 46(6), 32-38.

[3] Ha, H., \& Lee, O. (2019). An Empirical Study on Information Integration System Maturity Model for an Airport. International Journal of Engineering Research and Technology, 12(11), 2000-2008.

[4] Choi, P., Kang, J., \& Park, J. (2011). Analysis on Connection of Information Infra for Efficient Ubiquitous-service Realization. Journal of the Korean Society of Surveying, Geodesy, Photogrammetry and Cartography, 29(5), 497-507.

[5] Yoon, J. (2017). e-Government for Better Civil Services: How the Korean Government Implemented the e-Registration System. Global Delivery Initiative, 1-12.

[6] Melbourne Airport Deploys Real-Time Data to Support World-Class Customer Experience. (2017, 27 March 2017). NEWS. $\quad$ Retrieved from https://www.pcworld.idg.com.au/mediareleases/29330/melbo urne-airport-deploys-real-time-data-to/ Accessed: 2020-10-5

[7] T-Systems Support New Smart Airport - Beijing Daxing International Airport. (2019, October 31, 2019). NEWS. Retrieved from https://finance.yahoo.com/news/t-systemssupport-smart-airport-230000969.html?guccounter=1 Accessed: 2020-10-5

[8] Nucciarelli, A., \& Gastaldi, M. (2009). Collaboration in the airport business through the development of an IT platform. International Journal of Production Economics, 121(2), 562573.

[9] Whitten, J. L., \& Bentley, L. D. (2008). Introduction to systems analysis and design: McGraw Hill Irwin. 
International Journal of Engineering Research and Technology. ISSN 0974-3154, Volume 13, Number 10 (2020), pp. 2752-2760

(C) International Research Publication House. https://dx.doi.org/10.37624/IJERT/13.10.2020.2752-2760

[10] Agency, N. I. S. (2017). A Performance Measurement Manual for Information System Operation. Retrieved from https://www.mois.go.kr/frt/bbs/type001/commonSelectBoard Article.do?bbsId=BBSMSTR_000000000015\&nttId=60107\# none Accessed: 2020-10-5

[11] Park, S. (2005). Chulhwan Kim, Vice president of Incheon International Airport Corporation, NEWS. Computer World. Retrieved from http://www.comworld.co.kr/news/articleView.html?idxno=60 17 Accessed: 2020-10-5

[12] Incheon Airport. (2011). AURI Implementation Performance Report. Retrieved from https://www.kdevelopedia.org/resource/view/0420170512014 7727.do\#.X3qOamj7SUl Accessed: 2020-10-5

[13] Kwon, Y. (2017, September 10, 2017). Incheon Airport Terminal 2 opens in January next year... and system integration completed with Terminal 1, NEWS. Yonhap news. Retrieved from https://www.yna.co.kr/view/AKR20170910020400004 Accessed: 2020-10-5

[14] Kelemen, Z. (2009). Airport information system integration by using message broker. Periodica Polytechnica Transportation Engineering, 37(1-2), 15-21.

[15] Eriksen, P. (2002). Collaborative decision making information management in airports. Paper presented at the Proceedings. The 21st Digital Avionics Systems Conference.

[16] Rhoades, D. L., Waguespack, B., \& Young, S. (2000). Developing a quality index for US airports. Managing Service Quality: An International Journal.

[17] Second day of IT problems at Bristol Airport. (2018, September 15, 2018). NEWS. BBC NEWS. Retrieved from https://www.bbc.com/news/uk-england-bristol-45534104 Accessed: 2020-10-5

[18] Lee, M. (2015, March 27, 2015). Incheon International Airport is dreaming of becoming a hub in Northeast Asia by carrying out the third phase' project steadily. Information Technology NEWS. Retrieved from http://www.koit.co.kr/news/articleView.html?idxno=57780 Accessed: 2020-10-5

[19] Metcalfe, B. (2013). Metcalfe's law after 40 years of ethernet. Computer, 46(12), 26-31.

[20] Reed, D. P. (1999). That sneaky exponential-Beyond Metcalfe's law to the power of community building. Context magazine, 2(1).

[21] Odlyzko, A., \& Tilly, B. (2005). A refutation of Metcalfe's Law and a better estimate for the value of networks and network interconnections. Manuscript, March, 2, 2005.

[22] Zhang, X., Liu, J., \& Xu, Z. (2015). Tencent and Facebook data validate Metcalfe's law. Journal of Computer Science and Technology, 30(2), 246-251.

[23] Nickerson, J. V., \& Olariu, S. (2005). A Measure for Integration and Its Application to Sensor Networks. Paper presented at the 15th Workshop on Information Technologies and Systems WITS 2005.

[24] Jung, W., Lee, J., \& Kim, Y. (2010). An Assessment of Combat Effectiveness for C4I System Considering Network
Effect. Journal of the Society of Korea Industrial and Systems Engineering, 33(2), 23-32.

[25] Silver, M., Markus, M., \& Beath, C. (1995). The information technology interaction model: A foundation for the MBA core course. MIS quarterly, 361-390.

[26] Lee, O., \& Gong, S. (2004). Overcoming the Confucian psychological barrier in government cyberspace. CyberPsychology \& Behavior, 7(1), 25-28.

[27] Piccoli, G. (2012). Information Systems for Managers: Text and Cases, 2nd Edition: Text and Cases: John Wiley \& Sons.

[28] Chae, M., \& Kim, T. (2015). Factors affecting the development of hub airport clusters: focusing on the roles of low-cost carriers in the Asia-Pacific region. International Journal of Urban Sciences, 19(3), 305-319.

[29] Park, Y. (2003). An analysis for the competitive strength of Asian major airports. Journal of Air Transport Management, 9(6), 353-360.

[30] Loo, B. (2008). Passengers' airport choice within multiairport regions (MARs): some insights from a stated preference survey at Hong Kong International Airport. Journal of transport geography, 16(2), 117-125.

[31] Eie, W., Hong, J., \& Park, D. (2019). Evaluating the Competitiveness for Major International Airports in Northeast Asia. KSCE Journal of Civil Engineering, 23(2), 844-849.

[32] Atak, A., \& Kingma, S. (2011). Safety culture in an aircraft maintenance organisation: A view from the inside. Safety science, 49(2), 268-278.

[33] Meshkati, N. (1997). Human performance, organizational factors and safety culture. Paper presented on National Summit by NTSB on transportation safety.

[34] Licu, T., \& Grace-Kelly, E. (2009). ATM Safety Framework Maturity Survey Methodology for ANSPs. Edition 1 ed: Eurocontrol.

[35] Korea Institute of Public Finance. (2019). Evaluation report of Management performance for public enterprise in 2018 (Public enterprise 1). Retrieved from http://korea.kr/archive/expDocView.do?docId=38639 Accessed: 2020-10-5

[36] Incheon Airport. (2017). Incheon International Airport passes the key gateway for multiple terminal operation!. Retrieved from https://www.airport.kr/co/ko/cmm/cmmBbsView.do?PAGEI NDEX $=1 \&$ SEARCH_STR $=\& F N C T \_C O D E=121 \&$ SEARCH _TYPE $=\&$ SEARCH_FROM=2017.07.29\&SEARCH_TO $=20$ 18.07.29\&NTT_ID=22689 Accessed: 2020-10-5

[37] Sohn, S., Kim, K., \& Lee, C. (2013). User requirement analysis and IT framework design for smart airports. Wireless personal communications, 73(4), 1601-1611.

[38] Park, J., Kim, J., \& Shim, G. (2014). Supporting Air Transport Policies Using Big Data Analysis. The Korea Transport Institute, 1-218

[39] Shin, T., Kim, J., \& Lee, Y. (2016). Long-term Strategy and its Directions for Incheon International Airport. Journal of the Aviation Management Society of Korea, 14(3), 101-120. 